\title{
Modelling of Precipitation Hardening in Casting Aluminium Alloys
}

\author{
Linda $\mathrm{Wu}$ and W. George Ferguson \\ University of Auckland \\ New Zealand
}

\section{Introduction}

Precipitation hardening, because it involves the hardening of the material over a prolonged time, is also called age hardening, or ageing. By the appropriate heat treatment of precipitation hardening, the strength or hardness of some heat-treatable aluminium alloys can be enhanced by the formation of nano-meter sized second-phase precipitated particles within the original phase matrix. The fine precipitates in the alloy impede dislocation movement by forcing the dislocations to either cut through the precipitated particles or go around them. By restricting dislocation movement during deformation, the alloy is strengthened. Thus precipitation hardening is the most versatile and demanding heat treatment in aluminium alloys, either for wrought or casting alloys.

The precipitation-hardening process generally involves following three basic steps:

a. Solution heat treatment, or homogenization, is the first step where the alloy is heated between the solvus and solidus temperatures and soaked until all of the soluble phases are dissolved and a homogeneous solid-solution structure is produced.

b. Quenching is the second step where the solid solution is rapidly cooled to a lower temperature, usually room temperature. This forms the formulation of a supersaturated solid solution (SSSS) since the solubility of one or more alloying elements in aluminium decreases with decreasing temperature.

c. The final step in the precipitation hardening process is aging that allows controlled decomposition of the supersaturated solid solution (SSSS) and the formation of strengthening precipitates. It is the process where the supersaturated solution is heated below the solvus temperature to produce a finely dispersed precipitates. When ageing occurs at room temperature, it is called natural ageing. Ageing above room temperature is called artificial ageing.

With the age-hardening aluminium alloys having become the backbone of the automotive and aerospace industries, although a century has now elapsed since the phenomenon of age or precipitation hardening was discovered by the German metallurgist, Alfred Wilm (Wilm, 1911), new observations are still being made as the latest experimental techniques reveal more details of the actual atomic process involved. Precipitation hardening was hailed as the first nanotechnology (Polmear, 2006) and now it is possible to develop fine-scale microstructures in a much wider range of alloys through the use of novel processing methods. The optimization of material processing techniques has, however, for a long time, 
been pursued by trial and error. As it involves working blind, this method is costly and wasteful of manpower. It is desirable for material scientists to conduct fewer experiments to attain a specified goal. Fortunately, this has become possible with the development of materials and computer science.

Since the precipitation of second phase particles is critical to the properties of many industrially important aluminium alloys, modelling of precipitation kinetics and strengthening in age hardening aluminium alloys has gained considerable interest among researchers. During the precipitation process, three major physical elementary mechanisms are involved: i.e. nucleation, growth and coarsening. Based on how these three processes are treated, modelling of the precipitation kinetics in aluminium alloys can be divided into two main approaches. One of approaches is based on the Shercliff-Ashby process model (Shercliff \& Ashby, 1990a) in which only one average particle size is assumed and the three processes are considered in isolation with the implicit assumption that one process is essentially complete before the next one begins. Shercliff and Ashby first attempted to assemble a process model for the ageing of the simplest of the age-hardening aluminium alloys, by introducing a process model widely used in chemical engineering but relatively rare in processing of solid materials. Their process model draws together established knowledge of the kinetics of microstructure evolution with dislocation behavior, in order to determine the mechanical properties. This model gives a good description of some Al-Cu and Al-Mg-Si (Shercliff \& Ashby, 1990b) , wrought as well as casting alloys (Rometsch \& Schaffer, 2002) and also 8000 Al-Li aluminium alloys (Pandey, 1995).

In the other approach, which is more refined, Kampmann and Wagner have produced a numerical approach (KWN model) (Kampmann et al., 1987; Kampmann \& Wagner, 1984) capable of describing the particle size distribution (PSD) in the time domain, while dealing with the nucleation-growth-coarsening phenomena within the same formulation. Hence in the KWN model, the particle size is assumed to be a continuous parameter. And then a strength model is used to evaluate the resulting change in hardness or yield strength at room temperature by taking into account contributions from lattice resistance, solid solution hardening and precipitation hardening. Though the KWN model has been developed for a few decades and successfully applied to a number of aluminium alloy systems, such as 2xxx, 6xxx and 7xxx (Myhr \& Grong, 2000; Myhr et al., 2001; Robson, 2004a; Robson, 2004b) , however, most of modelling work has been focused on the wrought aluminium alloys and none modelling work has been applied to the casting aluminium alloys. In the present work, the KWN model has been for the first time applied to the casting aluminium alloys A356 and A357.

\section{Shercliff-Ashby process model}

\subsection{Components of the process model}

The complete Shercliff-Ashby model for isothermal age hardening includes the following components or - best called sub-models:

1. The initial growth of a volume fraction of precipitate, and consequent changes in solute concentration;

2. The dependence of the equilibrium volume fraction of precipitate on ageing temperature;

3. Precipitate coarsening by competitive growth;

4. The contribution of solid solution strengthening to the yield strength; 
5. The contribution of shearable precipitates to the strength; and

6. The contribution of non-shearable or bypassing precipitates to the strength (Orowan Strengthening).

The sub-models $(1) \sim(3)$ belong to the microstructure evolution. And the contributions to the strength model consist of the sub-models $(4) \sim(6)$.

\subsubsection{Precipitation from supersaturated solid solution}

After solution heat treatment and quenching, the non-equilibrium phase precipitates from the solid solution on ageing. During the early stages of precipitation, the initial precipitation kinetics are described by Shewmon (Shewmon, 1963): the mean solute concentration in the matrix $\bar{c}$ decays exponentially with time $\mathrm{t}$, raised to a power close to unity:

$$
\bar{c}(t)=c_{e}+\left(c_{i}-c_{e}\right) \exp \left(-t / \tau_{1}\right)
$$

where $c_{i}$ is the initial solute concentration, $c_{e}$ is the solute concentration at equilibrium at the ageing temperature, and $\tau_{1}$ is a temperature-dependent time constant.

The volume fraction $f$ of precipitate is directly proportional to solute loss $c_{i}-\bar{c}(t)$, tending to a final equilibrium value, $f_{e}$, when $\bar{c}=c_{e}$, thus:

$$
\frac{f(t)}{f_{e}}=\frac{c_{i}-\bar{c}(t)}{c_{i}-c_{e}}=1-\exp \left(-t / \tau_{1}\right)
$$

\subsubsection{The dependence of $f_{e}$ on ageing temperature}

The concentration of solute at the metastable solvus temperature $c_{s}$ is described by (Swalin, 1962):

$$
c_{s}=A_{0} \exp \left(-Q_{s} / R T_{s}\right)
$$

Where $A_{0}$ is a constant, and $Q_{s}$ is the free energy of solution of the solute, $T_{s}$ is solid solvus temperature.

The equilibrium concentration of solute $c_{e}$ at a temperature $T<T_{s}$ is:

$$
c_{e}=A_{0} \exp \left(-Q_{s} / R T\right)
$$

Dividing the above two equations gives the following equation:

$$
c_{e}=c_{s} \exp \left[-Q_{s}\left(\frac{1}{T}-\frac{1}{T_{s}}\right)\right]
$$

The equilibrium volume fraction of precipitate at temperature $T$ is given by:

$$
f_{e}=f_{\max }\left(\frac{c_{s}-c_{e}}{c_{s}}\right)
$$

where $f_{\max }$ is the maximum possible volume fraction precipitated at absolute zero. Substituting from equation (5): 


$$
f_{e}=f_{\max }\left\{1-\exp \left[-\frac{Q_{s}}{R}\left(\frac{1}{T}-\frac{1}{T_{s}}\right)\right]\right\}
$$

The above equation shows the dependence of $f_{e}$ on how far the ageing temperature $T$ lies below the (metastable) solid solvus temperature, $T_{s}$.

\subsubsection{Particle coarsening}

Since the coarsening of precipitates was first described by Ostwald (Ostwald, 1900), particle coarsening is often called Ostwald ripening. Most theories of Ostwald ripening are based on the classical works of Lifshitz and Slyozov (LS) (Lifshitz \& Slyozov, 1961) and of Wagner (Wagner, 1961), commonly referred to as LSW theory. The LSW theory predicts a cube law relating the mean particle radius $\bar{r}$ at time $t$ to that, $\bar{r}_{0}$, at time $\mathrm{t}=0$ :

$$
\bar{r}^{3}(t)-\bar{r}_{0}^{3}=\frac{c_{1} t}{T} \exp \left(-\frac{Q_{A}}{R T}\right)
$$

Where $c_{1}$ is a constant, $Q_{A}$ is the activation energy for volume diffusion of atoms between particles, $R$ the Universal gas constant $(8.314 \mathrm{~J} / \mathrm{mol} \mathrm{K})$ and $T$ the aging temperature.

\subsubsection{The contribution of the solid solution to the strength $\Delta \sigma_{s s}$}

For this strengthening mechanism, solute atoms of one element are added to another, resulting in either substitutional or interstitial point defects in the crystal. The substitution of solute atoms for aluminium atoms distorts the crystal lattice, hinders dislocation mobility and hence strengthens the alloy. The glide resistance caused by a solute at a mean concentration $\bar{c}$, expressed as a contribution to the yield strength, $\Delta \sigma_{s s}$, is given by (Friedel, 1964; Nabarro, 1967; Cottrell, 1964; Nabarro et al., 1979; Hospital, 1987; Hull \& Bacon, 2001):

$$
\Delta \sigma_{s s}=c_{2}\left[\bar{c}_{j}\right]^{2 / 3}
$$

where $c_{2}$ is a constant related to the size, modulus and electronic mismatch of the solute including various resolution factors, and $\bar{c}_{j}$, the mean solute concentration of a specific alloying element in the matrix.

\subsubsection{The contribution of shearable precipitates to the strength $\Delta \sigma_{A}$}

When particles are small, the dislocations will shear the precipitates, which is sometimes called precipitate resistance (Cahn et al., 1996). For this cutting mechanism, the contribution of shearable precipitates to the yield strength can be represented by:

$$
\Delta \sigma_{A}=c_{3} f^{m} \bar{r}^{n}=c_{3} f^{1 / 2} \bar{r}^{1 / 2}
$$

where $c_{3}$ is an alloy constant that depends on the particular strengthening mechanism, i.e., coherency, surface, chemical, stacking fault, and/or modulus hardening. The exponents $m$ and $n$ are always positive, for most dislocation particle interactions, both $m$ and $n$ have the values 0.5 (Starke, 1977; Sanders, 1980). 


\subsubsection{The contribution of bypassing precipitates to the strength $\Delta \sigma_{B}$}

When the precipitates grow during the precipitation the strength is increased and the dislocation can no longer cut the precipitates. The mechanism by which dislocations bypass precipitates was first proposed by Orowan (Orowan, 1948) and is referred to as the Orowan mechanism or dispersed particle strengthening. A simple (but adequate) form of the Orowan equation is:

$$
\Delta \sigma_{B}=\frac{c^{\prime} G b}{l}
$$

where $c^{\prime}$ is a constant, $G$ the shear modulus, and $b$ the Burgers vector. The particle spacing, $l$, in the slip plane of the dislocation is related to the volume fraction, $f$, and radius, $r$. Substituting $l=c " \frac{r}{f^{1 / 2}}$ (where $c "$ is a constant) into equation (11) gives:

$$
\Delta \sigma_{B}=c_{4} \frac{f^{1 / 2}}{r}
$$

where $c_{4}$ contains all the constants in equations (11) and $c$.

\subsection{Assembly of the process model}

In real alloys where a number of different strengthening mechanisms are operative at room temperature (Hatch et al., 1984), it is reasonable to assume that the individual strength contributions can be added linearly. Considering age hardening aluminium alloys, the following contributions are of importance, i.e., with precipitation hardening due to shearing and bypassing of particles by dislocations and solid solution hardening effects. Therefore, the resulting expression for the overall macroscopic yield strength $\sigma$ is:

$$
\sigma=\sigma_{i}+\sigma_{s s}+\sigma_{p p t}
$$

Where $\sigma_{i}$ is the intrinsic yield strength, which remains constant during ageing. $\sigma_{s s}$ is the solid solution strength and $\sigma_{p p t}$ is the precipitation hardening strength due to shearing and bypassing of particles by dislocations.

The method of assembling the process model is to combine the microstructure evolution of sub-models into the different contributions to the yield strength (Kocks et al., 1975; Martin, 1980), then identify the overall yield strength with the sum. Both mean solute concentration $\bar{c}$ and volume fraction $f$ vary with time, reaching steady values before the peak of the ageing curve is reached.

In order to combine the equations of sub-models together to give a process model for ageing, Shercliff and Ashby proposed the temperature corrected time, $P$, which was defined by:

$$
P=\frac{t}{T} \exp -\frac{Q_{A}}{R T}
$$

This parameter, referred to as "kinetic strength" by Ion et al.(Ion et al., 1984), measures the number of kinetic jumps that have taken place in time $t$. Over most of the ageing curve, the initial radius $r_{0}<<$ r, hence we may re-write equation (8): 


$$
r(t)=C_{1} P^{1 / 3}
$$

In the Shercliff-Ashby modeling work, the net contribution of precipitation to the strength from the shearing and bypassing precipitates was defined by taking their harmonic mean:

$$
\Delta \sigma_{p p t}=\left[\frac{1}{\Delta \sigma_{A}}+\frac{1}{\Delta \sigma_{B}}\right]^{-1}
$$

If define the value of $P$ corresponding to the peak strength as $P_{p}$ and the volume fraction $f$ reaches an equilibrium volume fraction $f_{e}$, then from the fact that the peak in the ageing curve lies very close to the point where the two contributions to peak strengthening are equal, $\Delta \sigma_{A}=\Delta \sigma_{B}$, and we can get $C_{3} f_{e}^{1 / 2} P_{P}^{1 / 6}=C_{4} f_{e}^{1 / 2} P_{P}^{-1 / 3}$, which gives the relationship:

$$
C_{4}=C_{3} P_{P}^{1 / 2}
$$

From the equation (17), we can conclude that the value of $P$ required to reach the peak over a wide range of temperature is often roughly constant. Its value can be found from equation (14) by substituting values for the times $t_{p}$ corresponding to the peaks of the ageing curves at several temperatures and taking the mean. Hence we use this value, $P_{p}$, to normalize the kinetic strength (noting that $P / P_{p}=1$ at the peak), equation (15) becomes:

$$
r(t)=C_{5}\left(\frac{P}{P_{p}}\right)^{1 / 3}
$$

Then another parameter $S_{0}$, the "peak precipitation strength" is introduced into the model and defined by:

$$
S_{0}=\frac{C_{3}}{2} f_{e}^{1 / 2} P_{p}^{1 / 2}
$$

Because $P_{p}$ is constant, $S_{0}^{2} \propto f_{e}$. Substituting $r$ and $S_{0}$ into equations (10) and (12) and then taking the harmonic mean gives:

$$
\Delta \sigma_{p p t}=\frac{2 S_{0}\left(P / P_{p}\right)^{1 / 6}}{1+\left(P / P_{p}\right)^{1 / 2}}
$$

Note that when $P=P_{p}, \Delta \sigma_{p}=S_{0}$, which defines the peak in the ageing curve.

Since $S_{0}^{2} \propto f_{e}$ and according to equation $f(t)=f_{e} *\left[1-\exp \left(-t / \tau_{1}\right)\right]$, by assuming the cubic coarsening law holds from the very beginning of precipitation even while the volume fraction is changing, and replacing $f_{e}$ by $f(t)$, gives a corresponding variation in $S^{2}$ :

$$
S^{2}(t)=S_{0}^{2}\left[1-\exp \left(-t / \tau_{1}\right)\right]
$$

From these equations it may deduced that when $t>>\tau_{1}, f(t)$ tends to $f_{e}$ and $S(t)$ has reached the peak precipitate strength, $S_{0}$. 
From equation (9), the initial solute concentration $c_{i}$ can be expressed in terms of the initial solid solution strength $\Delta \sigma_{s s i}$, that is, $c_{i}=c_{4} \Delta \sigma_{s s i}^{3 / 2}$; and similary equilibrium solute concentration $c_{e}$ can be expressed in terms of the final solid solution strength contribution $\Delta \sigma_{s s 0}$, that is, $c_{e}=c_{4} \Delta \sigma_{s s 0}^{3 / 2}$. Substituting these expressions into equation (1) gives:

$$
\bar{c}(t)=c_{4}\left[\Delta \sigma_{s s 0}^{3 / 2}+\left(\Delta \sigma_{s i}^{3 / 2}-\Delta \sigma_{s s 0}^{3 / 2}\right) \times \exp \left(-t / \tau_{1}\right)\right]
$$

Substituting this value into equation (9), the evolution of the corresponding solid solution strength is then described by:

$$
\Delta \sigma_{s s}(t)=\left[\Delta \sigma_{s s 0}^{3 / 2}+\left(\Delta \sigma_{s s i}^{3 / 2}-\Delta \sigma_{s s 0}^{3 / 2}\right) \times \exp \left(-t / \tau_{1}\right)\right]^{2 / 3}
$$

Experiments have shown that the volume fraction and solute concentration reach their equilibrium values at a time which is a constant fraction of the time to reach peak strength (Anderson, 1959). Therefore, the time constant $\tau_{1}$ in the equations can be scaled as $t_{p}$ :

$$
\tau_{1}=K_{1} t_{p}
$$

where $K_{1}$ is a constant.

Or using the definition of $P_{p}$ :

$$
\tau_{1}=K_{1} P_{p} T \exp \left(Q_{A} / R T\right)
$$

The peak precipitate strength $S_{0}$ depends on the ageing temperature because the volume fraction $f_{e}$ does so. Combining this with equation (21) gives:

$$
S_{0}^{2}(T)=\left(S_{0}\right)_{\max }^{2}\left\{1-\exp \left[-\frac{Q_{s}}{R}\left(\frac{1}{T}-\frac{1}{T_{s}}\right)\right]\right\}
$$

Combining equation (7) and (26) gives:

$$
S^{2}(t, T)=\left(S_{0}\right)_{\max }^{2}\left\{1-\exp \left[-\frac{Q_{s}}{R}\left(\frac{1}{T}-\frac{1}{T_{s}}\right)\right]\right\} \times\left[1-\exp -\left(t / \tau_{1}\right)\right]
$$

Similarly the solid solution contribution to the strength depends on the ageing temperature because it determines the amount of solute left in solution. The temperature-variation of the equilibrium solid solution component of the yield strength is:

$$
\begin{aligned}
\left(\Delta \sigma_{s s 0}\right)_{T} & =c_{2}\left(c_{e}\right)^{2 / 3} \\
& =\left(\Delta \sigma_{s s 0}\right)_{T_{s}} \exp \left[-\frac{2}{3} \frac{Q_{s}}{R}\left(\frac{1}{T}-\frac{1}{T_{s}}\right)\right]
\end{aligned}
$$

At $T=T_{s}$, the concentration of the matrix equals the alloy concentration, and there is no precipitate. In the as-quenched condition the alloy is a uniform solution of the full alloy content, hence the as-quenched strength, $\sigma_{q}$, is given by:

$$
\sigma_{q}=\sigma_{i}+\left(\Delta \sigma_{s s 0}\right)_{T_{s}}
$$


By combining equation (28) and (29) gives:

$$
\left(\Delta \sigma_{s s 0}\right)_{T}=\left(\sigma_{q}-\sigma_{i}\right) \exp \left[-\frac{2}{3} \frac{Q_{s}}{R}\left(\frac{1}{T}-\frac{1}{T_{s}}\right)\right]
$$

In the over-aged condition, the coarse precipitate contribute to the strength can be negligible, hence the over-aged strength $\sigma_{o a}$ depends only on the matrix solute concentration. Thus $\sigma_{o a}$ is the sum of the solid solution strength and the intrinsic strength of pure aluminium $\sigma_{i}$ :

$$
\left(\sigma_{o a}\right)_{T}=\sigma_{i}+\left(\Delta \sigma_{s s 0}\right)_{T}
$$

Combining equations (30) and (31) gives the variation of the over-aged strength with temperature:

$$
\left(\Delta \sigma_{o a}\right)_{T}=\sigma_{i}+\left(\sigma_{q}-\sigma_{i}\right) \exp \left[-\frac{2}{3} \frac{Q_{s}}{R}\left(\frac{1}{T}-\frac{1}{T_{s}}\right)\right]
$$

Using known values of $\sigma_{i}$ and $\sigma_{q}$, the over-aged strength can be calculated.

\subsection{Calibration of the model}

The most difficult aspect in application of the Shercliff-Ashby model is calibration of the constants used in the process model. There are six constants that need to be calibrated from ageing curves: activation energy for ageing $Q_{A}\left(\mathrm{KJ} \mathrm{mol}^{-1}\right)$, peak temperature-corrected time $P_{p}(\mathrm{~s} \mathrm{~K}-1)$, metastable solvus temperature $T_{s}\left({ }^{\circ} \mathrm{C}\right)$, solvus enthalpy $Q_{s}\left(\mathrm{KJ} \mathrm{mol}^{-1}\right)$, maximum strength parameter at absolute zero $\left(S_{0}\right)_{\max }(\mathrm{MPa})$, constant coefficient $K_{1}$ relating $\tau_{1}$ to $t_{p}$. These constants do not change with temperature for the specific alloy.

\subsubsection{Calibration $Q_{A}$ and $P_{p}$}

$Q_{A}$ and $P_{p}$ can be found by calibrating the data to the peaks of the ageing curves. The values of peak hardness $\sigma_{p}$ and the time to peak $t_{p}$ at various temperatures can be read from the ageing curves. By finding the time to peak $t_{p}$ at various temperatures, $P_{p}$ is

evaluated directly.
From equation (14) it can be deduced that $P_{p}=\frac{t_{p}}{T} \exp \left(\frac{-Q_{A}}{R T}\right)=$ cons $\tan t$, and taking natural
logs it becomes: logs it becomes:

$$
\ln P_{p}=\ln \left(t_{p} / T\right)-\left(Q_{A} / R T\right)
$$

By putting $x=1 / T$ and $y=\ln \left(t_{p} / T\right)$, an Arrhenius plot of $y$ against $x$ results in a straight line. The value of $Q_{A}$ can be derived from the slope $\left(Q_{A} / R\right)$. The value of $P_{p}$ can be either calculated from $y_{0}=\ln P_{p}$ when $x=0$, or taken as the mean value of $P_{p}$ at each temperature.

2.3.2 Calibration $\left(S_{0}\right)_{\max }, Q_{s}$ and $T_{s}$

The temperature dependence of the equilibrium volume fraction is contained in the parameter $S_{0}$ since $S_{0}^{2} \propto f_{e}$. From equation (26), by plotting $S_{0}^{2}$ against temperature enables 
us to find values for $\left(S_{0}\right)_{\max }$ and $T_{s}$. From the graph, at the intersection of the extrapolated curve with the temperature axis, $S_{0}^{2}=0$, and from equation (26), it can be deduced that $T=T_{s}$; at the intersection with the $S_{0}^{2}$ axis, $T=0$, it can be deduced that $S_{0}=\left(S_{0}\right)_{\max }$. When $\left(S_{0}\right)_{\max }$ and $T_{s}$ have been determined, the solvus enthalpy $Q_{s}$ for each ageing temperature can be calculated using:

$$
Q_{s}=\frac{-R}{\left(1 / T-1 / T_{s}\right)} \ln \left[1-\frac{S_{0}^{2}}{\left(S_{0}\right)_{\max }^{2}}\right]
$$

The main problem is how to determine the value of $S_{0}$ from the ageing curves. At peak ageing, $\left(\Delta \sigma_{p p t}\right)_{p}=S_{0}$. The peak precipitation strength contribution, $\left(\Delta \sigma_{p p t}\right)_{p}$, is found by subtracting the other contributions (solid solution $\Delta \sigma_{s s}$ and intrinsic $\sigma_{i}$ ) from the measured peak strength $\sigma_{p}$.

$$
\left(\Delta \sigma_{p p t}\right)_{p}=S_{0}=\sigma_{p}-\left(\Delta \sigma_{s S}+\sigma_{i}\right)
$$

At peak hardness, the other contribution to $\left(\Delta \sigma_{s s}+\sigma_{i}\right)$ is the over-aged strength $\sigma_{o a}$ since $f$ has reached its equilibrium value $f_{e}$ before the peak. The value of $\sigma_{o a}$, however, depends on the value of $Q_{s}$ and $T_{s}$ as described by equation (32), which are not known. Thus we have to use an iterative method. We first estimate the value of $\sigma_{o a}$ : it must lie between the as quenched strength $\sigma_{q}$ (when all the solute is in solution), and the intrinsic strength $\sigma_{i}$ (when no solute is left in solution). Thus:

$$
\left(\sigma_{o a}\right)_{e s t}=\left(\Delta \sigma_{s s 0}+\sigma_{i}\right)_{p}=\left(\sigma_{i}+\sigma_{q}\right) / 2
$$

Thus, using equation (36) an initial estimated value of $S_{0}$ is obtained by:

$$
\left(S_{0}\right)_{e s t}=\sigma_{p}-\left(\sigma_{o a}\right)_{e s t}
$$

For each ageing temperature, it is possible to get the value of $\left(S_{0}\right)_{\text {est }}$. A graph of $\left(S_{0}\right)_{\text {est }}^{2}$ against temperature $T$ is then plotted. From the graph, the first estimated values of $\left(S_{0}\right)_{\max }$ and $T_{s}$ are obtained and $Q_{s}$ is calculated from equation (34).

From these values of $Q_{s}$ and $T_{s}$, a better estimate of $\sigma_{o a}$ and $S_{0}$ may now the obtained using equations (36) and (37). The whole procedure is repeated until the fit between theory and data is satisfactory.

\subsubsection{Calibration of $K_{1}$}

It remains to determine the time constant $\tau_{1}$ which is related to the peak temperature corrected time by equation (25). The constant $K_{1}$ is adjusted to give the required decay. The decay of the solid solution component of the strength is then given by equation (23) with $\Delta \sigma_{s s i}=\sigma_{q}-\sigma_{i}$ and $\Delta \sigma_{s s 0}=\sigma_{o a}-\sigma_{i}$.

\subsection{Application of the model}

The modelling method is applied to casting alloys A356 and A357. All the processes for calibration and constructing the predicted ageing curves are programmed under MATLAB 
which is a large software package that has many advanced features built-in, and it has become a standard tool for many working in science or engineering disciplines.

\subsubsection{Input data}

The input data for each alloy includes its composition, as quenched strength $\sigma_{q}$ and the strength of $\sigma_{i}$, which is defined as being the sum of the intrinsic strength of pure aluminium and solid solution strengthening contributions which remain constant during ageing, as well as the information of ageing curves which includes temperature $T$, time to peak yield strength $t_{p}$ and the peak yield strength $\sigma_{p}$. All this information is used to calibrate the constants thus the predicted ageing curves for various temperatures can be constructed.

The most detailed data set available was from Rometsch, etc. (Rometsch \& Schaffer, 2002) for the ageing of casting alloy A356 \& A357 at various temperatures. The compositions (in wt.\%) are to be Al-7.0 Si-0.40Mg-0.13Fe-0.03Sr for A356 and Al-7.0 Si-0.60Mg-0.13Fe-0.03Sr for A357. The equilibrium precipitates are $\mathrm{Mg}_{2} \mathrm{Si}$. $\sigma_{i}$ is $43 \mathrm{MPa}$ and as quenched strength $\sigma_{q}=75 \mathrm{MPa}$ for A356 and $\sigma_{q}=85 \mathrm{MPa}$ for A357. All above data with a data set for peak time and yield strength at various temperatures are listed in Table $1 \&$ Table 2.

\begin{tabular}{|l|lcc|}
\hline Nominal composition of $\mathrm{Mg}(\mathrm{wt} \%)$ & 1.0 & & \\
\hline$\sigma_{i}(\mathrm{MPa})$ & 43 & & \\
\hline$\sigma_{q}(\mathrm{MPa})$ & 75 & & \\
\hline \multirow{5}{*}{ Ageing data } & Temperature & Time to peak & Peak YS \\
& $T\left({ }^{\circ} \mathrm{C}\right)$ & $t_{p}(\mathrm{~s})$ & $\sigma_{p}(\mathrm{MPa})$ \\
\cline { 2 - 4 } & 250 & 268 & 207 \\
& 230 & 699 & 239 \\
& 210 & 1630 & 256 \\
& 190 & 5188 & 271 \\
& 170 & 39,156 & 268 \\
& 150 & 263,090 & 272 \\
\hline
\end{tabular}

Table 1. Data used for calibration for A356

\begin{tabular}{|l|lcc|}
\hline Nominal composition of $\mathrm{Mg}(\mathrm{wt} \%)$ & 1.0 & & \\
\hline$\sigma_{i}(\mathrm{MPa})$ & 43 & & \\
\hline$\sigma_{q}(\mathrm{MPa})$ & 85 & & \\
\hline \multirow{5}{*}{ Ageing data } & Temperature & Time to peak & Peak YS \\
& $T\left({ }^{\circ} \mathrm{C}\right)$ & $t_{p}(\mathrm{~s})$ & $\sigma_{p}(\mathrm{MPa})$ \\
\cline { 2 - 4 } & 250 & 191 & 258 \\
& 230 & 503 & 277 \\
& 210 & 979 & 294 \\
& 190 & 4354 & 297 \\
& 170 & 34,026 & 300 \\
& 150 & 267,881 & 303 \\
\hline
\end{tabular}

Table 2. Data used for calibration for A357 


\subsubsection{Calibration results}

The calibration results for the alloys A356 and A357 using the above input data are listed in Table 3.

\begin{tabular}{|c|c|c|c|}
\hline Parameter & Symbol & A356 & A357 \\
\hline Activation energy for ageing $\left(\mathrm{KJ} \mathrm{mol}^{-1}\right)$ & $Q_{A}$ & 130.38 & 137.66 \\
\hline Peak temperature-corrected time (s K-1) & $P_{p}$ & $3.58 \times 10^{-14}$ & $4.36 \times 10^{-15}$ \\
\hline Metastable solvus temperature $\left({ }^{\circ} \mathrm{C}\right)$ & Ts & 269.59 & 286.66 \\
\hline Solvus enthalpy $\left(\mathrm{kJ} \mathrm{mol}^{-1}\right)$ & $Q_{s}$ & 55.39 & 50.30 \\
\hline $\begin{array}{l}\text { Maximum strength parameter at absolute } \\
\text { zero }(\mathrm{MPa})\end{array}$ & $\left(S_{0}\right)_{\max }$ & 229.70 & 259.34 \\
\hline Constant relating $\tau_{1}$ to $t_{P}$ & $K_{1}$ & 0.0990 & 0.1009 \\
\hline
\end{tabular}

Table 3. Calibration results for A356, A357

\subsubsection{Modelling results}

The contributions to the full ageing curve of the intrinsic strength, solid solution strength, and precipitation hardening due to shearable and non-shearable stresses for A356 at $175{ }^{\circ} \mathrm{C}$ are shown in Fig.1. The net contribution of precipitation to the strength from the shearing and bypassing precipitates was modelled by taking their harmonic mean.

After calibration, the ageing curves for different isothermal ageing temperatures for alloys A356 and A357 were modelled, as shown in Fig. 2 and Fig. 3 respectively. And the values of $t_{p}$ and $\sigma_{p}$ for the different Al-Mg-Si alloys are listed in Table 4.

\begin{tabular}{llllllll}
\hline Material & $\begin{array}{l}\text { Ageing } \\
\text { at } 50^{\circ} \mathrm{C}\end{array}$ & $\begin{array}{l}\text { Ageing } \\
\text { at } 100^{\circ} \mathrm{C}\end{array}$ & $\begin{array}{l}\text { Ageing } \\
\text { at } 150^{\circ} \mathrm{C}\end{array}$ & $\begin{array}{l}\text { Ageing } \\
\text { at } 175^{\circ} \mathrm{C}\end{array}$ & $\begin{array}{l}\text { Ageing } \\
\text { at } 190^{\circ} \mathrm{C}\end{array}$ & $\begin{array}{l}\text { Ageing } \\
\text { at } 210^{\circ} \mathrm{C}\end{array}$ \\
\hline A356 & $t_{p}$ (hour) & $10000^{*}$ & 2400 & 20.00 & 2.75 & 0.93 & 0.24 \\
& $\begin{array}{c}\sigma_{p}(\mathrm{MPa}) \\
\text { A357 }\end{array}$ & $100.26^{*}$ & 284.60 & 282.97 & 279.79 & 275.95 & 266.62 \\
& $t_{p}$ (hour) & $10000^{*}$ & 3000 & 19.00 & 2.33 & 0.74 & 0.18 \\
& $\sigma_{p}(\mathrm{MPa})$ & $104.22^{*}$ & 316.21 & 314.70 & 312.01 & 308.92 & 301.78 \\
\hline
\end{tabular}

$t_{p}$ is limited to 100000 hours, * means not to peak ageing yet.

Table 4. $t_{p}$ and $\sigma_{p}$ for ageing at different temperatures for A356, A357

From Fig. 2 and Fig. 3 and Table 4, we can see that:

a. The modelling results show that when ageing at a lower temperature, it takes a longer time to reach peak yield strength (or hardness), but the peak yield strength is higher, and vice versa. This is the basic ageing trend. 


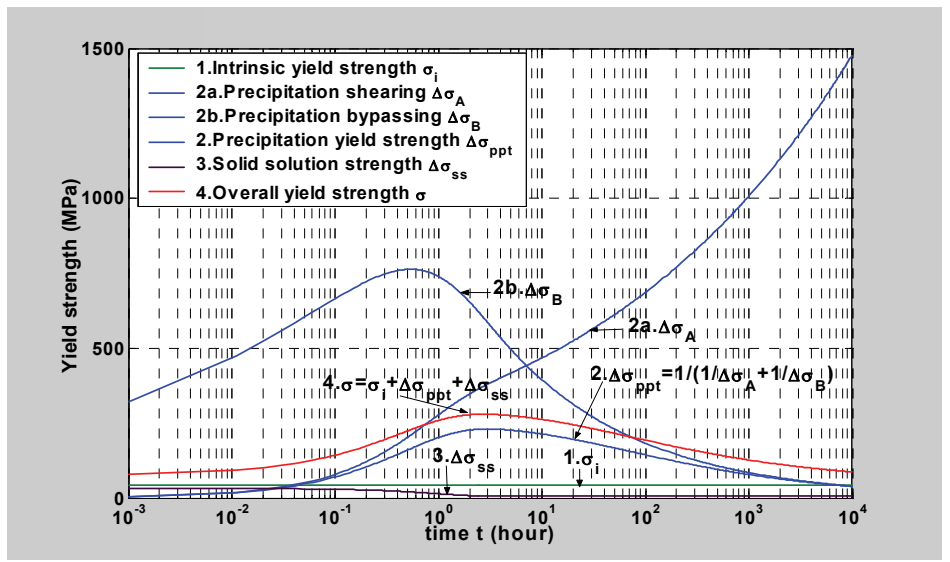

Fig. 1. Ageing curve of different contributions for A356 ageing at $175^{\circ} \mathrm{C}$

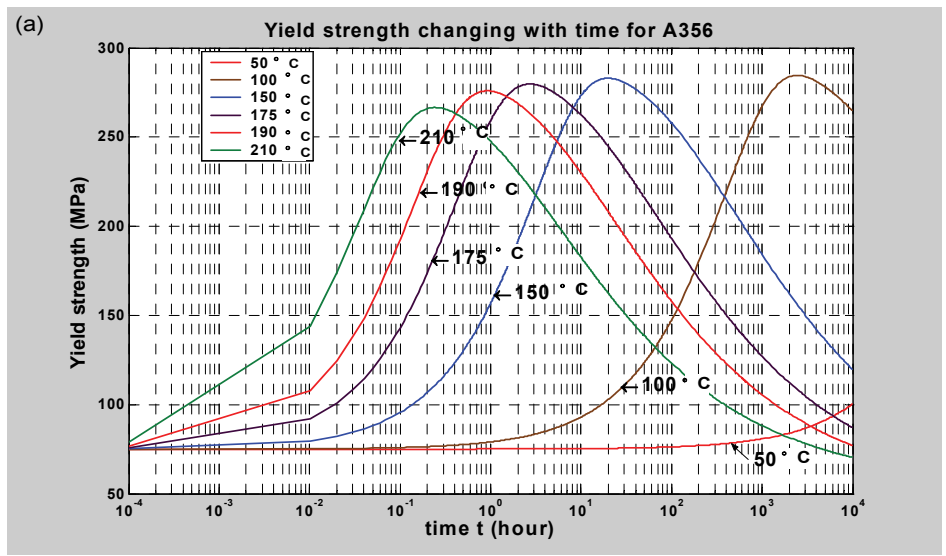

Fig. 2. Ageing at different temperatures for A356

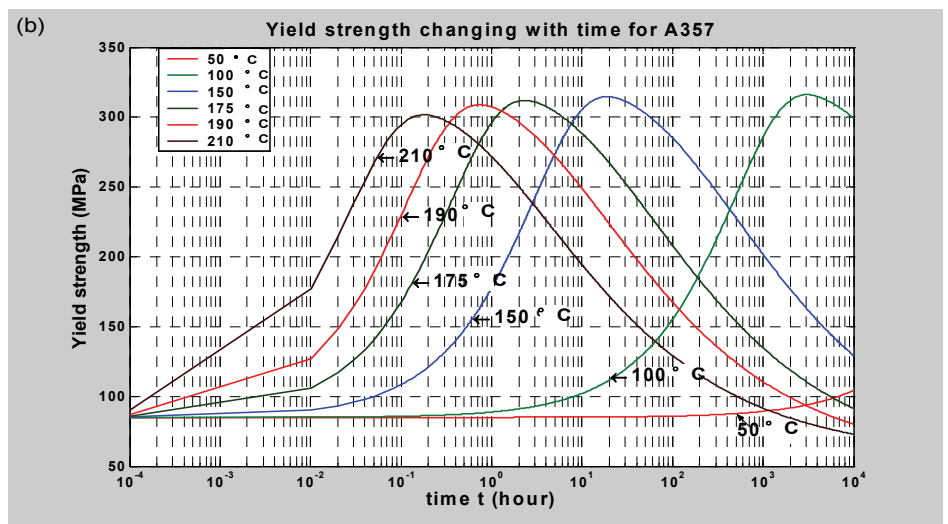

Fig. 3. Ageing at different temperatures for A357 
b. Time to the peak yield strength $t_{p}$ is very sensitive to the temperature; however, the peak yield strength $\sigma_{p}$ doesn't change much as temperature changes.

c. At low temperature (such as $50^{\circ} \mathrm{C}$ ), there is almost no yield strength or hardness gain for the initial of which means that the modeling results shows poor agreement with the experimental data at low temperatures.

\subsubsection{Model validation}

The modelling results are validated by ageing A356 at different temperatures, and recording hardness at different ageing times. The samples were cut from as cast A356 aluminium wheels, ground flat and the testing surfaces were finished with 1200 grit $\mathrm{SiC}$ paper.

The samples were solution treated in an unstirred salt bath at $540 \pm 3{ }^{\circ} \mathrm{C}$ for 75 minutes, then quenched in water to room temperature and aged without delay. Artificial ageing was carried out in an oil bath (for $150^{\circ} \mathrm{C}$ ) and salt baths (for $175^{\circ} \mathrm{C}, 210^{\circ} \mathrm{C}$ ) with a temperature variation of $\pm 2{ }^{\circ} \mathrm{C}$. At various times, a sample was removed from the bath then quenched in water to room temperature, and Rockwell hardness tests for Scale E and Scale K were done. For long ageing processes the samples were transferred to an air furnace after initial ageing in an oil or salt bath. Following heat treatment and before hardness testing, the artificial ageing samples were kept in a refrigerator, and natural ageing samples were kept at room temperature. The average value of at least five effective readings were used for each data point. The ageing curves for hardness are shown in Fig. 4.
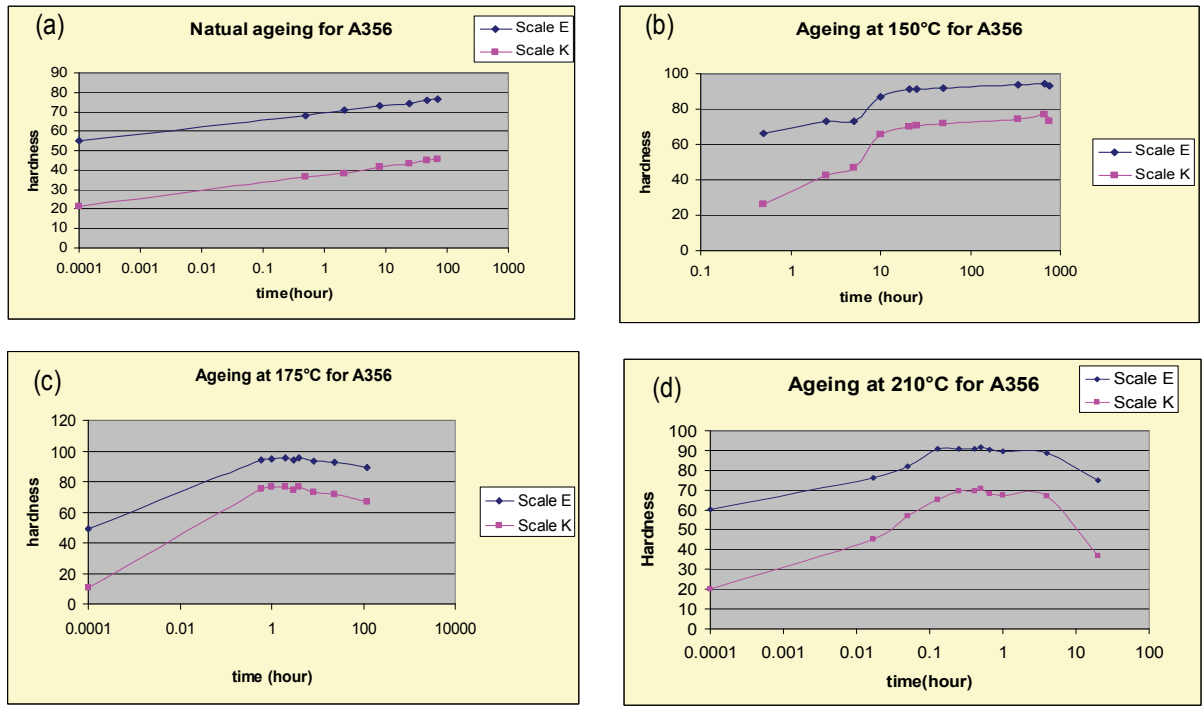

Fig. 4. Hardness changes with time for A356 at (a) Natural ageing; (b) $150^{\circ} \mathrm{C}$; (c) $175^{\circ} \mathrm{C}$; (d) $210^{\circ} \mathrm{C}$

From the above ageing curves, we can see that the experimental data is in good agreement with the modelling results for artificial ageing. However, for natural ageing, the hardness (or yield strength) increases with time, whereas the modeling curve shows almost no change for the initial 100 hours. This means that at lower temperature, the modeling results for Schercliff-Ashby method were in poor agreement with the experimental data. This could be 
due to two reasons: the first is that among the input data used for calibration there is no information for low temperatures; the other reason is that in the present model, the ageing curve is mainly controlled by particle coarsening, with negligible input from nucleation and growth. Because for low temperature, it may take a longer time to reach the process of particle coarsening, nucleation and growth can not be neglected. Therefore, for the present calibration of the Schercliff-Ashby modelling method it is recommended that it not be applied at low ageing temperature.

\section{Kampmann and Wagner Numerical model (KWN model)}

The KWN model consists of the following two distinct but integrated modules:

a. A microstructure model for prediction of the precipitation kinetics during ageing with coupled nucleation, growth and coarsening (and likewise dissolution) in dilute alloy systems, assuming spherical particles with uniform thermodynamic properties.

b. A strength model, which converts the relevant output parameters into an equivalent room temperature yield stress or hardness.

\subsection{Precipitation kinetics model}

Modelling Microstructure evolution is the first step of any integrated model for predicting the properties of a given material. The modelling of precipitation kinetics is based on the Kampmann and Wagner type numerical model (KWN model). It has a number of features that make it suitable for industrial process modelling.

The essential features of this model are summarized below (Robson et al., 2003; Robson, 2008; Robson, 2004b):

a. The continuous size distribution of the particles is subdivided into a large number of size classes $\left[R_{j}, R_{j+1}\right]$ containing $N_{j}$ particles respectively.

b. The continuous time evolution of the particle distribution is split up into a sequence of discrete time steps.

c. At each time step, the number of newly nucleated particles with the size of slightly above the critical radius is calculated using classical nucleation theory and allocated to an appropriate size class.

d. The growth of existing particles is calculated by assuming growth is diffusion controlled and spherical growth morphology. The influence of the Gibbs-Thomson effect is used to calculate the modified interfacial compositions for each size class at each time step. Therefore, the existing ones grow or shrink depending on their size.

e. Coarsening arises naturally in the model, and no simplifying assumptions for the shape of the particle size distribution are predesigned.

f. The change in matrix solute level due to precipitate formation or dissolution is calculated at each time step using the mean field approximation.

\subsubsection{Nucleation of new precipitates}

According to classic nucleation theory, the nuclei form as a result of localised compositional fluctuations that occur statistically within the supersaturated matrix. Provided that the incubation period can be neglected at the same time as possible effects of elastic coherency strains around the nucleated particles are ignored, the nucleation rate $j$ is conveniently expressed as (Myhr \& Grong, 2000; Myhr et al., 1998; Myhr et al., 2004; Myhr et al., 2001; Myhr et al., 2002): 


$$
j=j_{0} \exp \left[-\left(\frac{A_{0}}{R T}\right)^{3}\left(\frac{1}{i n\left(\bar{C} / C_{e}\right)}\right)^{2}\right] \exp \left(-\frac{Q_{d}}{R T}\right)
$$

where $j_{0}$ is a pre-exponential term, $A_{0}$ a parameter related to the potency of the heterogeneous nucleation sites in the parent material $(\mathrm{J} / \mathrm{mol}), Q_{d}$ the activation energy for diffusion, $\bar{C}$ the mean solute content in the matrix, and $C_{e}$ is the equilibrium solute content at the particle/matrix interface (given by the phase diagram), $\mathrm{R}$ universal gas constant (8.314 $\mathrm{J} / \mathrm{Kmol})$, $\mathrm{T}$ temperature $(\mathrm{K})$.

\subsubsection{Particle growth}

When a spherical particle of radius $r$ and solute concentration $C_{p}$ is embedded in a supersaturated solid solution of a mean concentration $\bar{C}$, it will either dissolve or grow, depending on whether the particle/matrix interface concentration $C_{i}$ exceeds $\bar{C}$ or not. According to the diffusion-controlled growth, under the mean field approximation, the growth rate of particles can be expressed as (Myhr \& Grong, 2000; Myhr et al., 2001; Myhr et al., 2004; Wagner et al., 1991):

$$
v=\frac{d r}{d t}=\frac{\bar{C}-C_{i}}{C_{p}-C_{i}} \frac{D}{r}
$$

The diffusion coefficient $D$ is calculated at a given temperature from:

$$
D=D_{0} \exp \left(\frac{-Q_{d}}{R T}\right)
$$

The influence of interfaces on equilibrium (i.e. the interface curvature) has to be taken into account. This is the Gibbs-Thomson effect that modifies the solubility limits given by equilibrium thermodynamics (phase diagram). Through the Gibbs-Thomson equation (Madras \& McCoy, 2003; Porter \& Easterling, 1992; Miyazaki et al., 1996; Myhr et al., 2001):

$$
C_{i}=C_{e} \exp \left(\frac{2 \gamma V_{m}}{r R T}\right)
$$

where $\gamma$ is the particle-matrix interface energy, and $V_{\mathrm{m}}$ is the molar volume of the particle. Based on the above equations, it is possible to obtain an explicit expression for the critical radius $r^{*}$ of a particle that neither will grow nor dissolve (Langer \& Schwartz, 1980):

$$
r^{*}=\frac{2 \sigma V_{m}}{R T}\left(\ln \left(\frac{\bar{C}}{C_{e}}\right)\right)^{-1}
$$

The radii of particles which nucleate in each time interval are tracked separately. As the fraction of solute in the matrix decreases during precipitation, the driving force for nucleation and growth of the precipitate particles decreases and the critical particle radius increases, reducing the nucleation rate with time. Because $r^{*}$ depends on the current value of $C_{\mathrm{e}}$, the thermal stability of the precipitates is sensitive to changes in the temperature during heat treatment. It follows that reheating promotes particle dissolution, whereas cooling or 
isothermal annealing favours nucleation, growth and coarsening in a successive manner. Thus in the KWN model, the applied thermal programme has a large influence on the evolution of the particle size distribution with time.

\subsubsection{Coarsening}

Coarsening arises naturally in the model when the average solute concentration in the matrix $\bar{C}$ becomes larger than the solute concentration at the precipitate/matrix interface $\mathrm{Ci}$, thus resulting in the dissolution of the smaller precipitates. Therefore, those particles which have a radius $<r^{*}$ will have a negative growth rate according to equation (39) and will thus start to shrink. Particles with a radius $>r^{*}$ will retain a positive growth rate and will continue to increase in size. When the size of a group of particles reaches zero they are removed from the size distribution.

\subsubsection{Mass balance}

Once the volume fraction is computed, from the mass balance relating the amount of solute tied up in particles to the amount of the solute drained from the matrix, we can calculate the mean concentration in the matrix phase $\bar{C}$ as:

$$
\bar{C}=\frac{\left(C_{0}-C_{p} f\right)}{(1-f)}
$$

where $f=\int_{0}^{\infty} \frac{4}{3} \pi r^{3} \phi d r(\phi)$ is the size distribution function) is the volume fraction. The newly obtained matrix composition is employed as an input for the thermodynamic computations in the next time step.

\subsection{Strength model}

After predicting the microstructure evolution, the second step is to derive reliable microstructure/properties relationships. I will consider here the case of the yield stress or hardness. The strength model considering particle size distribution also includes precipitation hardening due to shearing and bypassing of particles by dislocations $\sigma_{p}$ and solid solution hardening $\sigma_{s s}$.

\subsubsection{Precipitation hardening}

Pursuing the usual approach for determining the critical resolved shear stress (or yield strength) from the interaction of gliding dislocations with point obstacles (Ardell, 1985; Lloyd, 1985; Gerold, 1980), according to Deschamps and Brechet (Deschamps et al., 1998; Deschamps \& Brechet, 1998), the relationship between $\sigma_{p p t}$ and $\bar{F}$ is given as:

$$
\sigma_{p p t}=\frac{M \bar{F}}{b L}
$$

Where $\bar{F}$ denotes the mean obstacle strength and $\sigma_{p p t}$ the resulting increase in the overall macroscopic yield strength, $M$ is the Taylor factor and $b$ is the magnitude of the Burgers vector and $L$ is the mean effective particle spacing in the slip plane along the curved dislocation. The microstructural variables $\bar{F}$ and $L$ evolve with aging time and are themselves functions of other microstructural variables as well as aging temperature. 
Moreover, assuming a mono-dispersive system of spheres, the effective particle spacing $L$ in the slip plane can be expressed in terms of the mean particle size $\bar{r}$, the particle volume fraction $f$, and the mean obstacle strength $\bar{F}$ using the Friedel statistic (Friedel, 1964; Brown \& Ham, 1971) which applies best for low obstacle strengths, and relies on the assumption of a steady-state for the number of precipitates along the dislocation line in motion. Thus, equation (44) becomes (Wagner et al., 1991; Deschamps \& Brechet, 1998) :

$$
\sigma_{p p t}=\frac{M}{b \bar{r}}\left(2 \beta G b^{2}\right)^{-1 / 2}\left(\frac{3 f}{2 \pi}\right)^{1 / 2} \bar{F}^{3 / 2}
$$

where $G$ is the shear modulus of the aluminium matrix and $\beta$ is a constant close to 0.5 .

In the general case, where the alloy contains a mixture of weak (shearable) and strong (nonshearable) particles, the mean obstacle strength is conveniently defined as:

$$
\bar{F}=\frac{\sum_{i} N_{i} F_{i}}{\sum_{i} N_{i}}
$$

where $N_{i}$ is the number density of particles that belongs to a given size class $r_{i}$, and $F_{i}$ is the corresponding obstacle strength.

The obstacle strength depends on the mechanism of overcoming.

- In the case of particle shearing (weak particles), the obstacle strength can have a number of different dependencies on the particle radius, depending on the main interaction mechanism between the shearable particle and the dislocation. It is a fair approximation to assume that $F_{i}$ is proportional to the particle radius as long as $r$ is smaller than the critical radius for shearing $r_{c}$

$$
\bar{F}_{i}=2 \beta G b^{2}\left(\frac{r_{i}}{r_{c}}\right)
$$

- In the case of precipitate by-passing (strong particles, characterised by $r_{i}>r_{\mathrm{c}}$ ), the obstacle strength is constant

$$
\bar{F}_{i}=2 \beta G b^{2}
$$

\subsubsection{Solid solution hardening $\sigma_{s s}$}

In age hardening, aluminium alloys elements, such as $\mathrm{Mg}$, $\mathrm{Si}$ and $\mathrm{Cu}$ give rise to considerable solid solution strengthening. Provided that the contribution from each element is additive, the solid solution hardening potential of the alloy $\sigma_{s s}$ can be expressed as:

$$
\sigma_{s s}=\sum_{j} k_{j} C_{j}^{2 / 3}
$$

where $C_{j}$ is the concentration of a specific alloying element in solid solution and $k_{j}$ is the corresponding scaling factor.

\subsubsection{Overall yield strength and hardness}

In alloys where several strengthening mechanisms are operative at room temperature, it is reasonable to assume that the individual strength contributions can be added linearly. Thus, 
the resulting expression for the overall macroscopic yield strength $\sigma$ is the same as the equation (13) used in Shercliff-Ashby model.

Conversion from yield strength (MPa) to hardness (VPN) can then be done through a simple regression formula (Grong, 1997):

$$
H_{v}=0.33 \sigma_{y}+16.0
$$

\subsection{Application to the casting aluminium alloys}

Although the KWN model has been successfully applied to different aluminium alloys (Myhr et al., 2001; Robson, 2004a), there are no reports of application to casting aluminium alloys. The present modelling work is the first time that KWN model has been applied to the casting aluminium alloys A356 and A357 for different ageing temperatures and compared with the experimental data.

\subsubsection{Isothermal ageing}

The modelling work is applied to the casting alloys A356 and A357 with chemical composition of Al-7.0Si-0.40Mg-0.13Fe-0.03Sr and Al-7.0Si-0.62Mg-0.13Fe-0.03Sr (Rometsch \& Schaffer, 2002) by weight percentage respectively. The experimental data used to validate the model is obtained from the literature (Rometsch \& Schaffer, 2002) and our experimental data. The yield strength is taken as approximately three times the Rockwell hardness scale E for A356.

The modelling results for ageing at various temperatures for A356 and A357 are shown in Fig. 5 and Fig. 6.

By choosing suitable parameters used in the microstructural and strength models, the modelled yield strength results for A356 (Fig. 5) and A357 (Fig. 6) are in very good agreement with the experimental data from the literature as well as own data. Because of greater $\mathrm{Mg}$ content, if ageing at the same temperature, the peak yield strength is higher and the time to peak ageing is shorter for A357 than for A356.

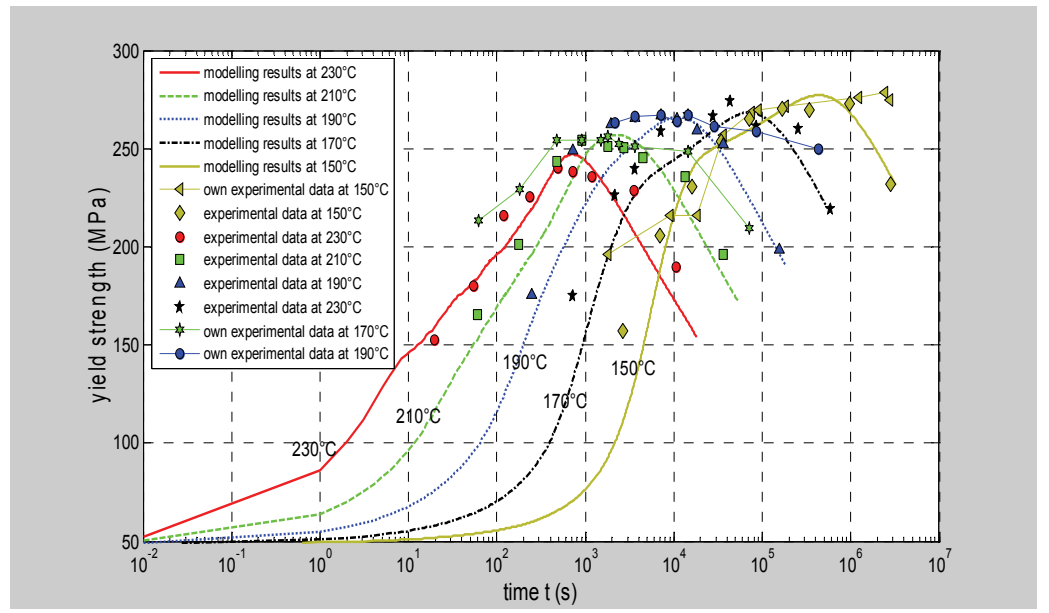

Fig. 5. Modelling results for ageing at various temperatures for A356 


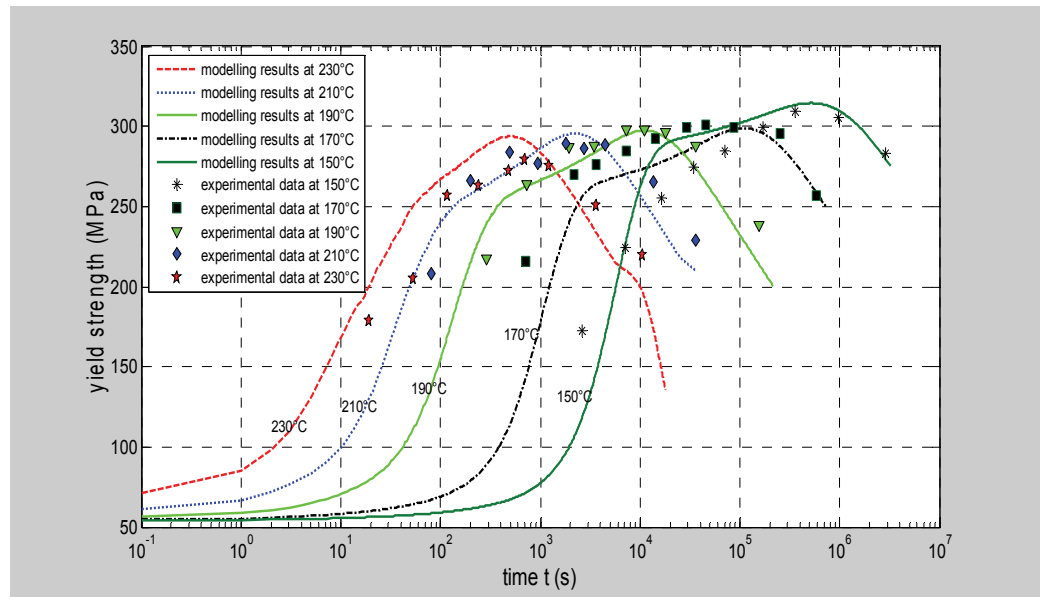

Fig. 6. Modelling results for ageing at various temperatures for A357

Fig. 7 gives the particle size distribution (PSD) after ageing at different temperatures for 3 hours for A356. For this time it is over-ageing for $210^{\circ} \mathrm{C}$ and $230^{\circ} \mathrm{C}$, peak-ageing for $190^{\circ} \mathrm{C}$ and under-ageing for $170^{\circ} \mathrm{C}$. The distribution broadens significantly in going from under ageing to over ageing. The evolution of PSD with time, as shown in Fig.8, indicates the particles gradually move to a larger size and therefore the broadness of the shape of distribution becomes greater with time evolution. Fig. 9 shows how the number of particles per unit volume changes with time at different temperatures.

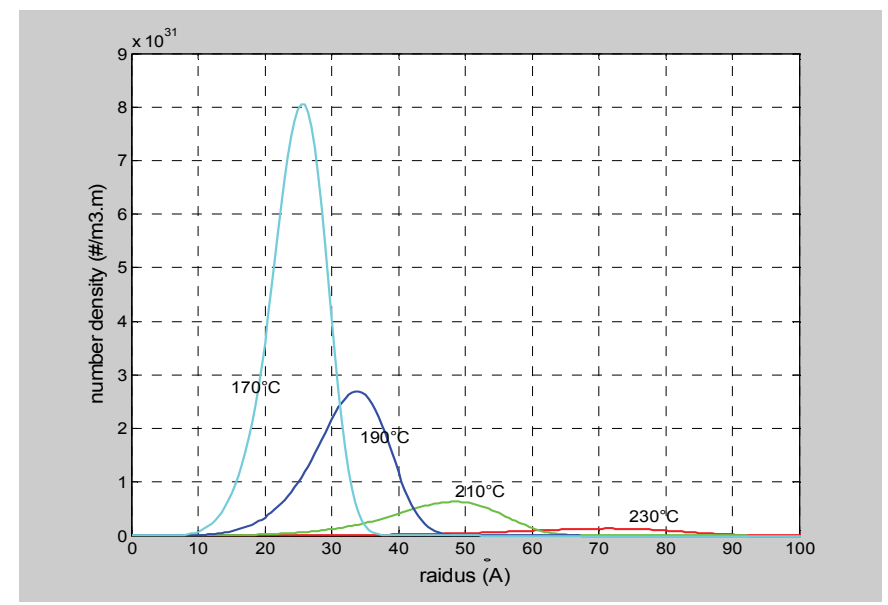

Fig. 7. Particle size distribution (PSD) after ageing: (a) 3 hours for different temperatures for A356 


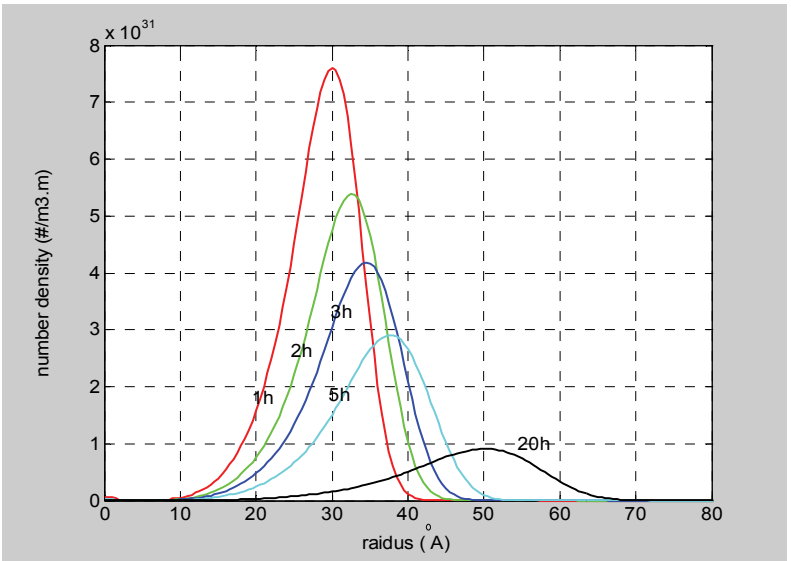

Fig. 8. Particle size distribution (PSD) after ageing different times at $190^{\circ} \mathrm{C}$ for A357

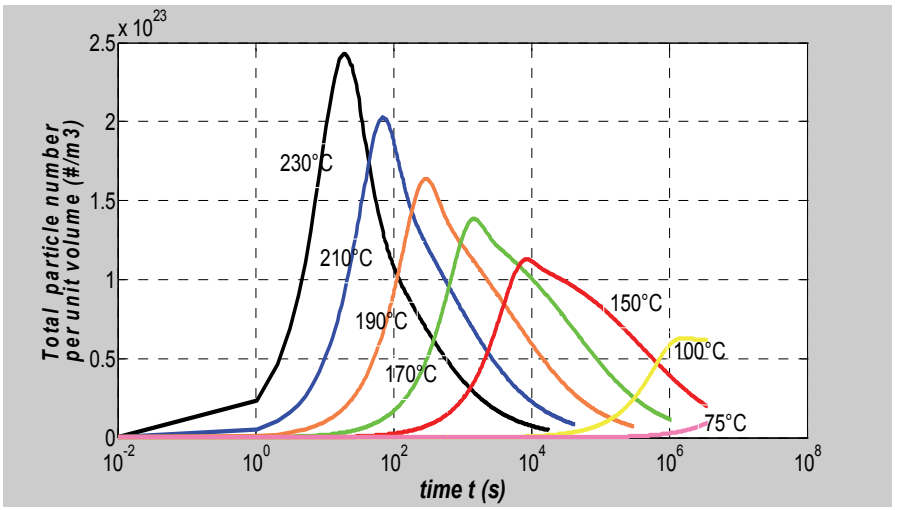

Fig. 9. Evolution of total number of particles per unit volume for ageing at different temperatures for A357

The total number of particles per unit volume increases to the peak value then decreases gradually. For higher temperature, it is faster to the peak value.

\section{Comparing with Shercliff-Ashby methodology}

Figures Fig.10 and Fig. 11 show the modelling results of yield strength under different ageing temperatures by the Schercliff-Ashby method and the KWN model for A356 and A357 respectively. The key for the figures is: ' $150-1^{\prime}$ stands for modelling at $150^{\circ} \mathrm{C}$ by method 1- KWN model, ' $150-2^{2}$ ' stands for modelling at $150^{\circ} \mathrm{C}$ by method 2- Schercliff-Ashby method, and ' $150-3^{\prime}$ ' stands for experimental data for ageing at $150^{\circ} \mathrm{C}$. Other symbols stand for the similar meanings. The experimental data is obtained from Rometsch \& Schaffer's work (Rometsch \& Schaffer, 2002).

From Fig. 10 and Fig. 11 we can see that most of the experimental data are located between the two modelling methods which means that the results simulated by both methods are in 


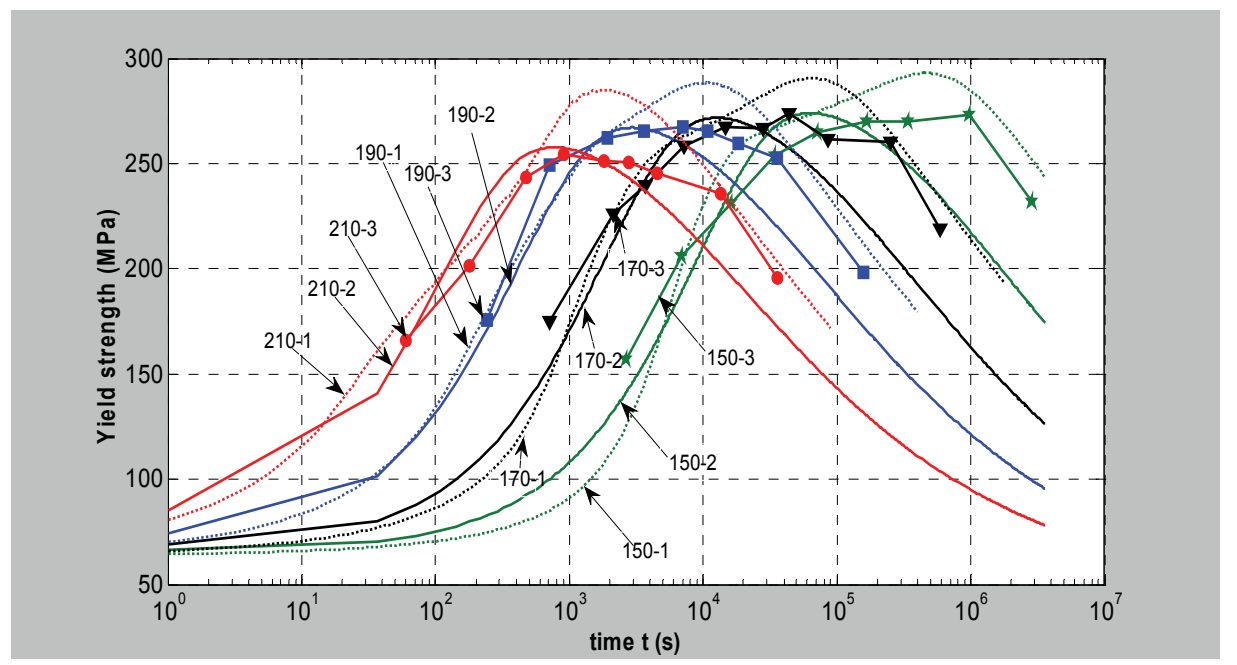

Fig. 10. Modelling of age hardening for $\mathrm{A} 356$ at ageing temperatures of $150^{\circ} \mathrm{C}, 170^{\circ} \mathrm{C}, 190^{\circ} \mathrm{C}$ and $210^{\circ} \mathrm{C}$ by Schercliff-Ashby method and KWN model, and comparasion with experimental data.

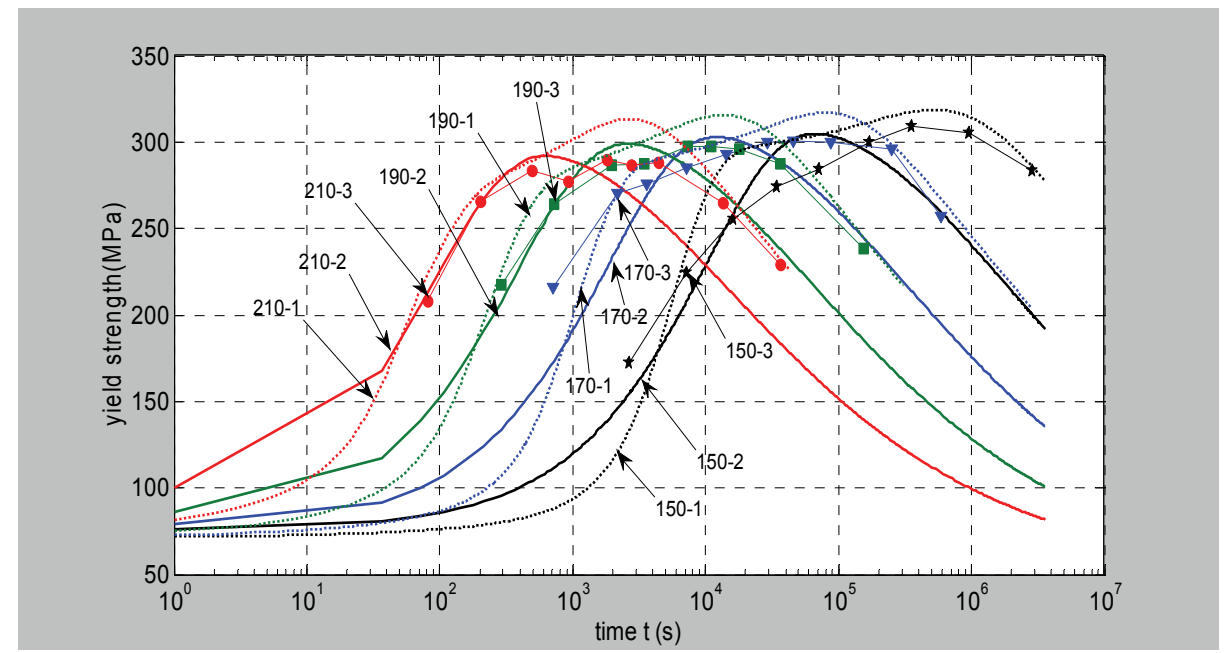

Fig. 11. Modelling of age hardening for $\mathrm{A} 357$ at ageing temperatures of $150^{\circ} \mathrm{C}, 170^{\circ} \mathrm{C}, 190^{\circ} \mathrm{C}$ and $210^{\circ} \mathrm{C}$ by Schercliff-Ashby method and KWN model, and comparasion with experimental data.

reasonable agreement with the experimental data. For the top part of the simulated ageing curve, the broadness is greater with the KWN model than the Schercliff-Ashby method. Therefore, the shape of ageing curves modelled by the KWN model are in closer agreement to the experimental data which means that the KWN model can give a better simulation of results. The reason for this is that the KWN model involves the whole precipitation process that is initiated by nucleation, then proceeds to particle growth and eventually ends with 
Ostwald coarsening. These three processes significantly overlap. The existing particles may grow or shrink depending on their size. If the particle size is greater than the critical size, it will grow; otherwise, it will dissolve. Whereas in the Schercliff-Ashby method, the particle size is only controlled by the Ostwald coarsening, no nucleation is considered. However, in the KWN model, not only the time is discretized, but also the continuous size distribution is subdivided into a large number of size classes, which results in a large amount in calculation time. Therefore, the Schercliff-Ashby method is faster than the KWN model. Normally, the Shercliff-Ashby method can be completed in a few minutes, whereas for KWN model, may take about one day to finish the calculation. Moreover, since most constants used in the equations are calibrated from ageing data, the modelled peak yield strength is more accurate for the Schercliff-Ashby method than the KWN model. Furthermore, some constants determined by calibration in the Schercliff-Ashby method, such as activation energy $Q_{A}$, solvus enthalpy $Q_{s}$, solvus temperature $T_{s}$, can also be used in the KWN model. But only when there exist series ageing data, which means series peak yield strength - ageing time to peak yield strength can we use the Schercliff-Ashby method.

\section{Conclusions}

In the Shercliff-Ashby process model, the most important and difficult part is to calibrate the constants used in the equations from the systematic experimental data (ageing curves). Since lack of information at low temperature for calibration, the modeling results were in poor agreement with the experimental data at low temperatures.

The Kampmann and Wagner numerical (KWN) model can be applied to not only wrought aluminium alloys, but also the casting alloys, such as A356 and A357. By choosing suitable parameters used in the microstructural and strength model, the modelling results are in good agreement with the experimental data obtained from the literature as well as own experimental data. This is the first time that the KWN model has been applied to the casting aluminium alloys.

For the casting aluminium alloys A356 and A357, the modelling results simulated by the KWN model are in better agreement with the experimental data than that by the SchercliffAshby method. However, the Schercliff-Ashby method can provide more accurate peak yield strength values and some constants calibrated in the Schercliff-Ashby method can also be used in the KWN model. Therefore, these two modelling methods complement each other.

\section{Reference}

Anderson, W.A., (1959) Precipitation from solid solution, ASM, metals park, Ohio

Ardell, A. (1985) Precipitation hardening. Metallurgical and Materials Transactions A, 16, 2131.

Brown, L.M. \& Ham, R.K. (1971) Dislocation-Particle Interactions, in Strengthening methods in crystals, eds Kelly, A. and Nicholson, Robin. Amsterdam, New York,: Elsevier Pub. Co.

Cahn, R.W. \& Haasen, P. (1996) Physical metallurgy. Elsevier Science Publishers, NorthHolland, Amsterdam; New York.

Cottrell, A. (1964) Theory of crystal dislocations. New York: Gordon and Breach.

Deschamps, A. \& Brechet, Y. (1998) Influence of predeformation and ageing of an Al-Zn-Mg alloy-- II. Modeling of precipitation kinetics and yield stress. Acta Materialia, 47, 293.

Friedel, J. (1964) Dislocations, Pergamon Press 
Gerold, V. (1980) Precipitation Hardening ,Dislocations in Solids, 4, 219.

Grong, O. (1997) Metallurgical Modeling of Welding. The Institute of Materials, London, second ed.

Hatch, J.E. (1984) Aluminum : properties and physical metallurgy. Metals Park, Ohio: American Society for Metals.

Hospital, J.T. (1987) Dislocations. St. Lucia, Qld.: University of Queensland.

Hull, D. \& Bacon, D.J. (2001) Introduction to dislocations, 4th edn. Oxford [Oxfordshire] ; Boston: Butterworth-Heinemann.

Ion, J.C.; Easterling, K.E. \& Ashby, M.F. (1984) A second report on diagrams of microstructure and hardness for heat-affected zones in welds. Acta Metallurgica, 32, 1949.

Kampmann, R.; Eckerlebe, H. \& Wagner, R., (1987) Precipitation Kinetics in Metastable Solid Solutions-Theoretical Considerations and Application to $\mathrm{Cu}-\mathrm{Ti}$ Alloys. In: Phase Transitions in Condensed Systems--Experiments and Theory: 525. Boston, Massachusetts; USA; .

Kampmann, R. \& Wagner, R., (1984) Kinetics of Precipitation in Metastable Binary AlloysTheory and Application to Cu-1.9at\% Ti and Ni-14at\% Al. 91.

Kocks, U.F.; Argon, A.S. \& Ashby, M.F. (1975) Thermodynamics and Kinetics of Slip. Progress in Materials Science, 19, 1.

Langer, J.S. \& Schwartz, A.J. (1980) Kinetics of nucleation in near-critical fluids. Physical Review A, 21, 948.

Lifshitz, I.M. \& Slyozov, V.V. (1961) The kinetics of precipitation from supersaturated solid solutions. Journal of Physics and Chemistry of Solids, 19, 35.

Lloyd, D.J. (1985) Precipitation Hardening. Strength of Metals and Alloys (ICSMA 7), 3, 1745.

Madras, G. \& McCoy, B.J. (2003) Temperature effects for crystal growth: a distribution kinetics approach. Acta Materialia, 51, 2031.

Martin, J.W. (1980) Micromechanisms in particle-hardened alloys. Cambridge ; New York: Cambridge University Press.

Miyazaki, T.; Koyama, T. \& Kobayashi, S. (1996) A new characterization method of the microstructure using the macroscopic composition gradient in alloys. Metallurgical and Materials Transactions A, 27, 945.

Myhr, O.R. \& Grong, O. (2000) Modelling of non-isothermal transformations in alloys containing a particle distribution. Acta Materialia, 48, 1605.

Myhr, O.R.; Grong, O. \& Andersen, S.J. (2001) Modelling of the age hardening behaviour of Al-Mg-Si alloys. Acta Materialia, 49, 65.

Myhr, O.R.; Grong, Ø.; Fjær, H.G. \& Marioara, C.D. (2004) Modelling of the microstructure and strength evolution in Al-Mg-Si alloys during multistage thermal processing. Acta Materialia, 52, 4997.

Myhr, O.R.; Grong, Ø.; Klokkehaug, S. \& Fjær, H.G., ( 2002) Mathematical Modelling of Weld Phenomena. Bhadeshia, H.K.D.H. (Ed.). London: Maney Publishing.

Myhr, O.R.; Kluken, A.O.; Klokkehaug, S.; Fjaer, H.G. \& Grong, O. (1998) Modeling of microstructure evolution, residual stresses and distortions in 6082-T6 aluminum weldments. Welding Journal ; VOL. 77 ; ISSUE: 7 ; PBD: Jul 1998, pp. 286.s.

Nabarro, F.R.N. (1967) Theory of crystal dislocations. Oxford,: Clarendon P.

Nabarro, F.R.N.; Duesbery, M.S. \& Hirth, J.P. (1979) Dislocations in solids. Amsterdam ; New York: North-Holland Pub. Co. 
Orowan, E. (1948) Symposium on Internal Stresses in Metals and Alloys, Session III discussion.

Ostwald, W. (1900) Über die Vermeintliche Isomeric des Roten und Gelben Quecksilberoxyds und die Oberflächenspannung Fester Körper. Z. Phys. Chem., 34, 495.

Pandey, A.D., (1995) A process model for age-hardening in aluminum-lithium alloy AA8090. The University of Regina (Canada), Canada.

Polmear, I.J. (2006) Light alloys : from traditional alloys to nanocrystals, 4th edn. Amsterdam ;: London : Elsevier Butterworth-Heinemann.

Porter, D.A. \& Easterling, K.E. (1992) Phase transformations in metals and alloys, 2nd edn. London ; New York: Chapman \& Hall.

Robson, J.D. (2004a) Microstructural evolution in aluminium alloy 7050 during processing. Materials Science and Engineering A, 382, 112.

Robson, J.D. (2004b) Modelling the overlap of nucleation, growth and coarsening during precipitation. Acta Materialia, 52, 4669.

Robson, J.D. (2008) Modelling precipitation in zirconium niobium alloys. Journal of Nuclear Materials, 377, 415.

Robson, J.D.; Jones, M.J. \& Prangnell, P.B. (2003) Extension of the N-model to predict competing homogeneous and heterogeneous precipitation in Al-Sc alloys. Acta Materialia, 51, 1453.

Rometsch, P.A. \& Schaffer, G.B. (2002) An age hardening model for Al-7Si-Mg casting alloys. Materials Science and Engineering A, 325, 424.

Sanders, T.H., 1980, Stone Mountain, Ga.

Shercliff, H.R. \& Ashby, M.F. (1990a) A process model for age hardening of aluminium alloys--I. The model. Acta Metallurgica et Materialia, 38, 1789.

Shercliff, H.R. \& Ashby, M.F. (1990b) A process model for age hardening of aluminium alloys--II. Applications of the model. Acta Metallurgica et Materialia, 38, 1803.

Shewmon, P.G. (1963) Diffusion in solids. New York,: McGraw-Hill.

Starke, E.A. (1977) Aluminium alloys of the 70's: Scientific solutions to engineering problems. An invited review. Materials Science and Engineering, 29, 99.

Swalin, R.A., (1962) Thermodynamics of Solids. Wiley, New York

Wagner, C. (1961) Theorie der alterung von niederschlägen durch unlösen. Z. Elektrochem, $65,581$.

Wagner, R.; Kampmann, R. \& voorhees, P.W., (1991) Homogeneous second-phase precipitation. In: Materials science and technology : a comprehensive treatment. Cahn, R.W.;Haasen, P. \& Kramer, E.J. (Eds.). Wiley-VCH, Weinheim.

Wilm, A. (1911) Physikalisch-metallurgische untersuchungen über magnesiumhaltige aluminiumlegier ungen. Metallurgie, 8, 225. 


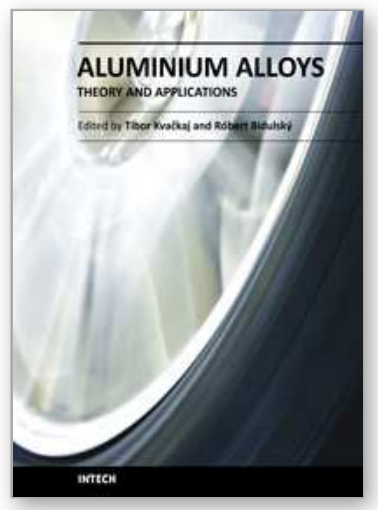

\author{
Aluminium Alloys, Theory and Applications \\ Edited by Prof. Tibor Kvackaj
}

ISBN 978-953-307-244-9

Hard cover, 400 pages

Publisher InTech

Published online 04, February, 2011

Published in print edition February, 2011

The present book enhances in detail the scope and objective of various developmental activities of the aluminium alloys. A lot of research on aluminium alloys has been performed. Currently, the research efforts are connected to the relatively new methods and processes. We hope that people new to the aluminium alloys investigation will find this book to be of assistance for the industry and university fields enabling them to keep up-to-date with the latest developments in aluminium alloys research.

\title{
How to reference
}

In order to correctly reference this scholarly work, feel free to copy and paste the following:

Linda Wu and W. George Ferguson (2011). Modelling of Precipitation Hardening in Casting Aluminium Alloys, Aluminium Alloys, Theory and Applications, Prof. Tibor Kvackaj (Ed.), ISBN: 978-953-307-244-9, InTech, Available from: http://www.intechopen.com/books/aluminium-alloys-theory-and-applications/modelling-ofprecipitation-hardening-in-casting-aluminium-alloys

\section{INTECH}

open science | open minds

\section{InTech Europe}

University Campus STeP Ri

Slavka Krautzeka 83/A

51000 Rijeka, Croatia

Phone: +385 (51) 770447

Fax: +385 (51) 686166

www.intechopen.com

\section{InTech China}

Unit 405, Office Block, Hotel Equatorial Shanghai

No.65, Yan An Road (West), Shanghai, 200040, China 中国上海市延安西路65号上海国际贵都大饭店办公楼 405 单元

Phone: +86-21-62489820

Fax: $+86-21-62489821$ 
(C) 2011 The Author(s). Licensee IntechOpen. This chapter is distributed under the terms of the Creative Commons Attribution-NonCommercialShareAlike-3.0 License, which permits use, distribution and reproduction for non-commercial purposes, provided the original is properly cited and derivative works building on this content are distributed under the same license. 